\title{
Acetaminophen Measurement
}

National Cancer Institute

\section{Source}

National Cancer Institute. Acetaminophen Measurement. NCI Thesaurus. Code C135398.

The determination of the amount of acetaminophen in a biological sample. 